RESEARCH PAPER RP860

\author{
Part of Journal of Research of the National Bureau of Standards, Volume 16, \\ February 1936
}

\title{
A SUMMARY OF INFORMATION ON THE PREPARATION AND PROPERTIES OF PURE IRON
}

\author{
By John G. Thompson and Harold E. Cleaves
}

\section{ABSTRACT}

A critical review of available information leads to the conclusion that really pure iron-iron free from significant amounts of all impurities-never has been prepared. Consequently many of the fundamental properties of iron cannot be defined with the accuracy desirable for such an important metal.

Available information on the preparation and properties of the purest available forms of iron is summarized in this paper.

\section{CONTENTS}

Page

I. Introduction 106

II. What is pure iron?

III. High-purity iron_._.

1. Basic open-hearth iron 108

2. Electrolytic iron

3. Laboratory irons $\ldots \ldots \ldots \ldots$

4. Other high-purity irons _... 109

5 . Summary of the methods of preparation of high-purity iron

IV. Properties of iron

1. Atomic properties

2. Allotropy 110

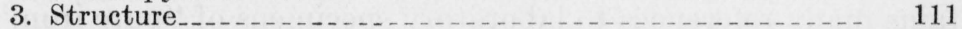

4. Density 112

5. Compressibility _._. 113

6. Melting point and heat of fusion $\ldots \ldots \ldots \ldots \ldots$

7. Boiling point and heat of vaporization

8. Mechanical properties

(a) Tensile properties

(b) Elastic properties _......................... 114

(c) Hardness $\ldots \ldots \ldots \ldots \ldots \ldots \ldots \ldots \ldots$

(d) Strength in compression $\ldots \ldots 115$

(e) Resistance to impact

(f) Endurance............ 117

(g) Effect of aging

9. Heat treatment

(a) Quenching

(b) Annealing 118

10. Plastic deformation

11. Thermal properties

(a) Specific heat_.............. 121

(b) Thermal conductivity ................ 123

(c) Thermal expansivity _............... 123

(d) Thermal electromotive force $\ldots \ldots \ldots \ldots 124$

12. Resistivity

13. Emissivity

14. Magnetic properties

15. Resistance to corrosion

16. Miscellaneous properties. 128

V. Selected references $\ldots \ldots \ldots \ldots \ldots$ 


\section{INTRODUCTION}

One of the metallurgical researches in progress at the National Bureau of Standards is the determination of the fundamental properties of elemental iron. The extraordinarily important role of the metal, iron, and its alloys in modern industrial life necessitates the acquiring and compiling of adequate and accurate data on this subject. The work is in progress in three stages, (1) the evaluation of existing data, representing the combined efforts in the past of numerous investigators working under a great variety of conditions, by a critical review of the existing scattered information in the technical literature, (2) the preparation in the laboratory of metallic iron of definitely known purity and perhaps of higher purity than has been available heretofore, and (3) the determination of properties of this metal to supplement present available information. The first stage of the project has been completed and the available information from the technical literature is summarized in the present paper. ${ }^{1}$ The preparation of high-purity iron is now in progress in the laboratorythe determination of its properties will follow. These phases of the project will be described in subsequent papers.

\section{WHAT IS PURE IRON?}

The designation "pure iron" has been applied at various times to a variety of ferrous materials. At one time the term connoted either sponge iron, preferably of Swedish origin, or wrought iron; later "pure iron" was used as a synonym for electrolytic iron; at present the term is used in a commercial sense to refer to open-hearth iron despite the fact that carbonyl iron, which is of considerably higher purity, is also available. However, carbonyl iron is not yet comparable to open-hearth iron in the quantity produced nor in price.

In addition to these commercial irons, the technical literature contains many references to laboratory specimens of "pure iron." Analyses of these were seldom made, however, partly from disinclination to sacrifice a large portion of the material for analytical samples and also because the precautions observed in the preparation were assumed to insure the purity of the product.

Much of the confusion as to what constitutes "pure iron" can be attributed to the changing opinion regarding pure metals in general. From earliest times, the common metals have been produced by smelting processes. The metal produced by smelting is always contaminated in some degree, by impurities either in the ore or introduced during the smelting operation. The degree of purification varies widely; gold of high purity can be produced by pyrometallurgical processes relatively easily, but the difficulties are intensified in the case of iron by the high temperatures required for smelting and the great affinity of molten iron for elements such as carbon, silicon, manganese, sulphur, and phosphorus. The presence of certain impurities in most metals was formerly considered unavoidable and therefore unimportant, but recently there has been an increasing apprecia-

1 The review of available information from the technical literature is presented in more detail in the recently published volume, The Metal-Iron. This is one of the series of monographs which, when completed, will constitute a complete and critical review of available information in regard to iron and its important alloys. The series of monographs is being published by the Iron Alloys Committee of the Engineering Foundation; The Metal-Iron is a contribution of the National Bureau of Standards to the program of the Iron Alloys Committee. 
tion of the marked effect of very small amounts of impurities and minor constituents on the properties of metals.

Recognition of this importance in the case of iron undoubtedly has been delayed by the fact that the properties such as strength, hardness and magnetic properties of slightly contaminated iron are superior to those of commercially pure metal. Only recently, in attempts to determine the fundamental properties of iron, particularly the magnetic properties, has it been shown that apparently insignificant amounts of impurities such as carbon, oxygen and sulphur may be of considerable importance. Cioffi $(57)^{2}$ reported that the sulphur absorbed at $1,300^{\circ} \mathrm{C}$ from an atmosphere containing 0.05 percent of hydrogen sulphide reduced the permeability of iron to less than one-third of its initial value. Still more striking is the conclusion of Yensen and Ziegler (72) that the presence of 0.002 percent of carbon reduced the maximum permeability of iron to approximately one-half that of the carbon-free metal. They found also that the first traces of oxygen exert a pronounced effect on the permeability although oxygen is about one-fifth as potent as carbon in this respect; an oxygen content of 0.01 percent reduced the permeability by approximately 50 percent.

It is evident on the basis of such data that the use of the adjective "pure" should be limited to metal that is known to be free from all impurities, in other words, to metal that approaches "elemental" iron in purity. From this point of view, pure iron is an unattained ideal; the best accomplishment to date is high-purity iron, not pure iron.

\section{HIGH-PURITY IRON}

Iron which may be classed as of high purity has been prepared by a number of investigators. However, the purity can seldom be stated with exactness; only recently has the need for complete analyses of extreme accuracy been recognized. Such analyses are difficult and entirely satisfactory methods are not always available. Since the applicability of chemical analysis is limited by the purity of available reagents, reliable results can be obtained only when the constituent to be determined is present in an appreciably greater amount than the blank correction which must be applied. For example, the determination of carbon in an amount of the order of 0.002 percent is extremely difficult with available methods, yet this amount of carbon is decidedly significant in its effect on the magnetic properties of iron. Spectrochemical analysis for the detection of important elements such as carbon, oxygen, and sulphur, to which the spectroscope is relatively insensitive, is very difficult and of doubtful value. Determinations of certain properties, magnetic, thermal, or electrical, have been proposed as criteria of purity but, as yet, the proposed methods of this kind have not been satisfactorily developed. An entirely reliable method for determining the degree of purity of high-purity iron still remains to be developed. The lack of accurate information on the composition of various high-purity irons from different sources or prepared by different metbods renders their comparison extremely difficult.

${ }^{2}$ The figures in parentheses here and throughout the text refer to the list of selected references at the end of the paper. 


\section{BASIC OPEN-HEARTH IRON}

The one type of high-purity iron for which extended commercial application has been found is open-hearth iron. The composition of Standard Sample 55 of the National Bureau of Standards, representing open-hearth iron, is shown in table 1. The presence of so many elements in determinable amounts is evidence of unusual care and completeness in the analysis rather than of impurity of this particular specimen. Several of the elements reported are not ordinarily determined in the analysis of ferrous materials. Open-hearth iron of this degree of purity, roughly 99.85 percent of iron, is the optimum result obtained to date by pyrometallurgical methods. Corresponding information on charcoal irons and sponge irons is not available. However, the incomplete analyses which are available indicate that the purity of the products analyzed, aside from occluded slag particles, was somewhat less than that of open-hearth iron.

TABLE 1-Composition of basic open-hearth iron

[National Bureau of Standards Standard Sample 55]

\begin{tabular}{|c|c|}
\hline Element & $\begin{array}{l}\text { Percent- } \\
\text { age }\end{array}$ \\
\hline $\begin{array}{l}\text { Oxygen } \\
\text { Copper } \\
\text { Nickel } \\
\text { Manganese } \\
\text { Sulphur } \\
\text { Carbon } \\
\text { Arsenic } \\
\text { Tin } \\
\text { Cobalt } \\
\text { Nitrogen } \\
\text { Phosphorus } \\
\text { Chromium } \\
\text { Molybdenum } \\
\text { Aluminum } \\
\text { Antimony } \\
\text { Silicon. }\end{array}$ & $\begin{array}{l}0.07 \\
.041 \\
.020 \\
.019 \\
.017 \\
.013 \\
.012 \\
.008 \\
.006 \\
.004 \\
.003 \\
.002 \\
.002 \\
.002 \\
.002 \\
.001\end{array}$ \\
\hline $\begin{array}{l}\text { Total of impurities deter- } \\
\text { mined. }\end{array}$ & 0.222 \\
\hline
\end{tabular}

2. ELECTROLYTIC IRON

Electrolytic iron has been produced in a number of processes varying widely in aim and scope of operation and in detail. Much of this work was done before the importance of very complete analyses was recognized, consequently the available analyses are in general decidedly incomplete. Cain, Schramm, and Cleaves (10) were the first to report nickel and cobalt, now recognized as major impurities in most electroly tic irons. Recent reports $(53,59)$ from the National Physical Laboratory in England, where the production of very pure iron has been under investigation for a number of years, state that metal containing 0.033 percent of impurities ( 0.022 percent of nickel, 0.006 percent of carbon, 0.003 percent of chromium, 0.001 percent of phosphorus, 0.0008 percent of copper, 0.0005 percent of silicon, and no sulphur or manganese, with no mention of oxygen) is considered to be about the best obtainable by electrodeposition. Electrolytic iron of this composition is of somewhat higher purity than the earlier electrolytic irons, although a review of the incomplete analyses 
reported in the literature indicates that the total of impurities in hydrogen-free electrolytic irons of good quality was consistently less than 0.1 percent. The purity of electrolytic iron by difference is assumed to be 99.9 percent or above, a value somewhat superior to that of open-hearth iron.

\section{LABORATORY IRONS}

Many attempts have been made to produce small amounts of extremely pure iron by careful purification of a compound of iron with subsequent reduction to metal. The two specimens which probably represent the purest iron ever produced were prepared by laboratory methods. These are the irons prepared about 1910 by Lambert and Thomson (2) for studies of the theory of corrosion, and by Baxter and Hoover (3) about 1912 for a determination of the atomic weight of iron, which is accepted as one of the best ever made. Both processes consisted essentially in elaborate purification of ferric nitrate, conversion of this compound to oxide, and reduction by means of purified hydrogen. Results of analyses of the irons were not reported and belief in their high purity is based on the precautions observed in the preparation and on the properties exhibited by the metal.

Much of the difficulty encountered in the application of these laboratory methods occurs in the reduction of the purified compound and in the melting of the resulting metal. Because of this the Physikalisch-Technische Reichsanstalt (1) in 1909 concluded that electrolytic methods were preferable to laboratory methods as a practical means of producing high-purity iron; on the other hand, according to recent reports $(53,59)$ the opposite conclusion has been reached by the National Physical Laboratory. The National Bureau of Standards has adopted a method similar to that of Lambert and Thomson or of Baxter and Hoover, but operated on a larger scale, as the most promising for the production of iron of really high purity.

\section{OTHER HIGH-PURITY IRONS}

Carbonyl iron, prepared in Germany according to processes described by deLangeron (26), Mittasch (34), Pincass (38), and Winter (51), has recently become available in quantity. It has been claimed that this iron is substantially free from all impurities except carbon and oxygen; other elements being absent either because they do not form volatile compounds or because their volatile compounds, if present, do not decompose under the conditions which obtain in the decomposition of iron carbonyl. Recent examination, at the National Bureau of Standards, of a few selected specimens of carbonyl iron showed that these specimens contained small but determinable amounts of several metallic elements as well as of nonmetallic constituents, but nevertheless were of high purity. Oxygen was not determined in these samples; the total of the impurities determined was roughly 0.015 percent in each case. These analyses are substantiated by the data given by Wells, Ackley, and Mehl (70), but additional evidence is desired to establish fully the purity and uniformity of carbonyl iron.

Sublimation processes are applicable for the purification of certain metals such as magnesium and manganese, but, according to Kroll (63), not for the preparation of pure iron. 
Maintaining solid iron in an atmosphere of purified hydrogen at a nigh temperature for a prolonged period has been used to reduce the carbon, sulphur, oxygen, phosphorus and nitrogen contents. Metallic impurities are not reduced in amount by this treatment. Iron treated in this manner exhibits superior magnetic properties as stated by Cioffi (58) and others.

In the study of pure iron, if it is ever obtained, it will be desirable to use single-crystal specimens for the determination of certain properties. The most successful method for the production of large crystals of iron is the "strain-anneal" method used by Edwards and Pfeil (17). While this method was successful with small flat specimens of iron of only fair purity, subsequent attempts by Gries and Esser (36) and by Ziegler (42) with larger specimens of vacuummelted electrolytic iron were not entirely successful.

\section{SUMMARY OF THE METHODS OF PREPARATION OF HIGH- PURITY IRON}

The purest irons ever produced are believed to be those prepared by Lambert and Thomson and by Baxter and Hoover by small-scale laboratory operations. However, the high degree of purity of these specimens is an assumption based on the method of preparation, precautions taken, and properties of the metal; analyses of the products were not reported. Available information indicates that the best electrolytic iron contained less than 0.1 percent total of impurities, electrolytic iron thus being slightly superior in purity to open-hearth iron. The degree of purity of carbonyl iron is very high but has not been definitely established.

\section{PROPERTIES OF IRON}

Since pure iron has never been prepared in useful quantities, its fundamental properties have not been directly determined. Likewise, the purest irons that have been prepared have been available in amounts too small to permit the determination of many properties. The following summary of the best available information on the properties of pure iron, in some instances is based on specimens of electrolytic iron; in some instances available information is limited to the properties of basic open-hearth iron.

\section{ATOMIC PROPERTIES}

Iron is number 26 in the periodic table of the elements and is placed in the eighth group associated with cobalt and nickel.

Its atomic weight is 55.84 (56). Aston (48) has concluded that there are two isotopes of mass 56 and 54, respectively, the latter being about 5 percent as abundant as the principal isotope. ${ }^{3}$

Iron forms two series of chemical compounds, ferrous and ferric, in which the iron is bivalent and trivalent, respectively.

\section{ALLOTROPY}

X-ray studies have established the existence of three allotropic modifications of solid iron, each being stable within a definite temperature range; alpha iron at ordinary temperatures, gamma at intermediate temperatures, and delta at temperatures which approach the melting point.

8 In a recent article, Proc. Roy. Soc. (London) 149, 396 (1935), Aston identified a third isotope of mass 57 , about 3 percent as abundent as the principal isotope. 
The change of the alpha allotrope to the gamma form and vice versa, which was termed the $A_{3}$ transformation by Osmond in 1890 , was formerly believed to occur over a rather wide range of temperature because the transformation on heating, $\mathrm{Ac}_{3}$, was observed at a higher temperature than the reverse change, $\mathrm{Ar}_{3}$, on cooling. It has now been established that the divergence between these two observed temperatures can be attributed to two factors, too rapid a rate of heating or cooling and the presence of impurities in the iron. Both of these factors affect the $\mathrm{Ar}_{3}$ temperature more than they do the $\mathrm{Ac}_{3}$ temperature. Recent work with samples of high-purity iron heated and cooled at very slow rates has shown that the $\mathrm{Ac}_{3}$ and $\mathrm{Ar}_{3}$ temperatures coincide within the limits of experimental error. A critical review of available information has established the most probable value for the temperature of the $\mathrm{A}_{3}$ transformation as $910^{\circ} \mathrm{C}\left(1,670^{\circ}\right.$ F). Data have been published indicating that $A_{3}$ in very pure iron occurs at a temperature appreciably higher than $910^{\circ} \mathrm{C}$, but according to a recent announcement the high value, $930^{\circ} \mathrm{C}$, obtained in one of these investigations was affected by an unsuspected pyrometric error. Correction for this error gave a value for $A_{3}$ close to $910^{\circ} \mathrm{C}$. Furthermore, Wells, Ackley, and Mehl (70) recently showed that several samples of the purest iron available all transformed at $910^{\circ} \mathrm{C}$. Accurate knowledge of the temperature of the $A_{3}$ transformation, of course, forms the fundamental basis of the heat treatment of ferrous metals.

At $1,400^{\circ} \mathrm{C}\left(2,550^{\circ} \mathrm{F}\right)$, the $\mathrm{A}_{4}$ transformation, the gamma allotrope changes to the delta form, which is stable at all temperatures up to the melting point.

In addition to the allotropic transformations at 910 and $1,400^{\circ} \mathrm{C}$, there is an important change in the magnetic properties of iron at about $770^{\circ} \mathrm{C}$, the $A_{2}$ point. This change from ferromagnetic to paramagnetic iron is a reversible one like the allotropic transformations but, since no change in crystalline structure occurs, both ferromagnetic and paramagnetic iron being the alpha allotrope, this change is called a magnetic transition, not a transformation.

Suggested additional transformations at temperatures other than $A_{3}$ and $A_{4}$, based on observed irregularities in the properties of iron, have not been confirmed by X-ray studies, and some of the irregularities have been definitely associated with the presence of impurities. According to Heindlhofer (61) no allotropic change in iron below $0^{\circ} \mathrm{C}$ has ever been observed.

\section{STRUCTURE}

Crystallographic studies of iron crystals indicated that iron crystallizes in the cubic or isometric system. X-ray studies have confirmed this and in addition established the atomic arrangement of alpha iron as body-centered cubic, the lattice constant being 2.861 angstrom units at $20^{\circ} \mathrm{C}$ and about 2.90 just below the $\mathrm{A}_{3}$ temperature.

$\mathrm{X}$-ray studies at temperatures above $\mathrm{A}_{3}$ have shown that gamma iron has a face-centered cubic structure and that at temperatures above $\mathrm{A}_{4}$ delta iron has a body-centered cubic structure like alpha iron. The $\mathrm{A}_{3}$ change is accompanied by an increase in the lattice constant, from about 2.90 angstrom units for alpha iron to about 3.64 for gamma iron. With increasing temperature the lattice 
constant of gamma iron increases, the value being about 3.68 angstrom units at the $\mathrm{A}_{4}$ point. The lattice constant of delta iron is about 2.92, this value agreeing approximately with an extrapolation from data on the effect of temperature on the lattice constant of alpha iron.

The normal microstructure of alpha iron, or ferrite, is that characteristic of pure metals in general - allotriomorphic crystalline grains. Various unusual features such as a fibrous, columnar, conical, or broken structure have been observed in electrolytic iron, as deposited, but investigations such as that of Blum and Rawdon (15) have shown that these are determined primarily by the conditions of electrodeposition. They are not inherent characteristics of the metal. Remelted electrolytic iron has a microstructure comparable to that of ferrite from other sources.

Certain unusual features termed veining or network structures have been observed $(28,35)$ within the ferrite grains examined under ordinary conditions. Alpha veining, an indistinct "phantom" network superimposed upon the ordinary alpha structural pattern, is a common occurrence in electrolytic and open-hearth iron and is generally considered to be associated with the fact that the metal has undergone the alpha-gamma transformation. However, some observers (65) believe that the presence of impurities is primarily responsible for alpha veining. A network pattern which appears to be associated with the previous existence of the metal in the gamma and delta states also has been observed in etched ferrite grains. Examples of these various structural features are shown in figure 1. The effect of these features on the mechanical properties is believed to be insignificant.

Twinning occurs readily in coarse-grained open-hearth iron deformed by impact, but only occasionally in purer forms of iron.

The microstructure of iron can also be revealed by heat-etching, i. e., if a polished specimen is heated in an evacuated chamber at a high temperature, slight volatilization occurs, this being somewhat greater at the grain boundaries so that an outline of the crystal pattern is formed. The effect is sometimes intensified by the volume change which accompanies the $A_{3}$ transformation, a slight "buckling" of the surface being the visible result.

A Widmanstätten or martensitic structural pattern can be developed in basic open-hearth iron by quenching from about $1,400^{\circ} \mathrm{C}$, but the development of these structures is apparently dependent on the presence of a small amount of carbon. Tritton (30) could not produce this feature in low-carbon electrolytic iron and in the recent work of Mehl and Smith (64) with electrolytic iron, success in its development was reported to be sporadic and unpredictable.

\section{DENSITY}

Values of the density of iron have been obtained by direct determination with specimens of the highest purity obtainable, by extrapolation to zero impurities of results obtained from a series of irons or alloys, and by calculation based upon determinations of the lattice constant. The results of the best determinations by all three methods are in good agreement and indicate that $7.87 \mathrm{~g} / \mathrm{cm}^{3}$ is the best present approximation for the density of pure iron. 


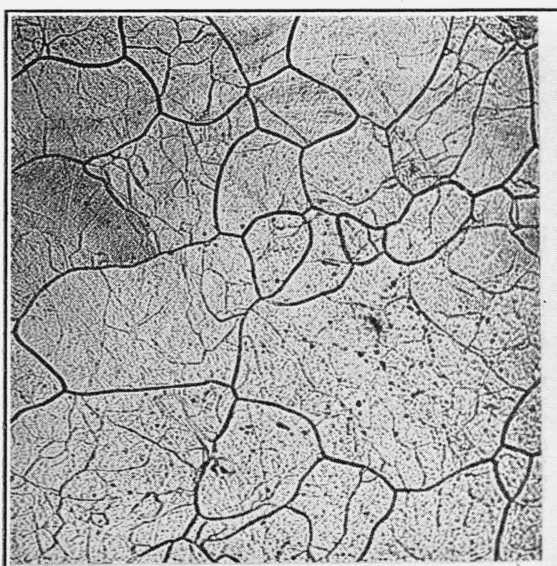

A

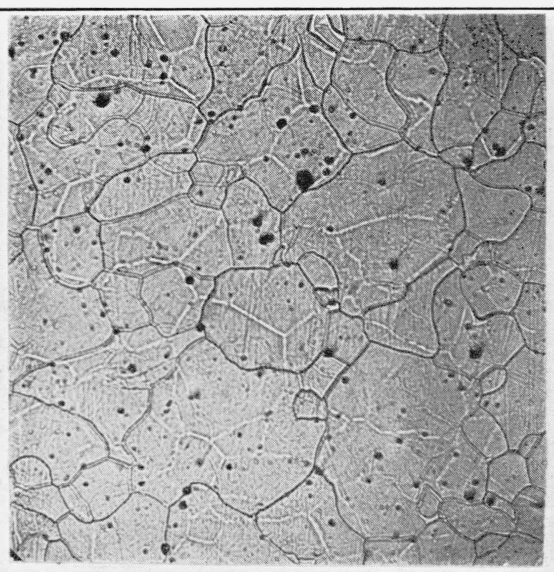

B

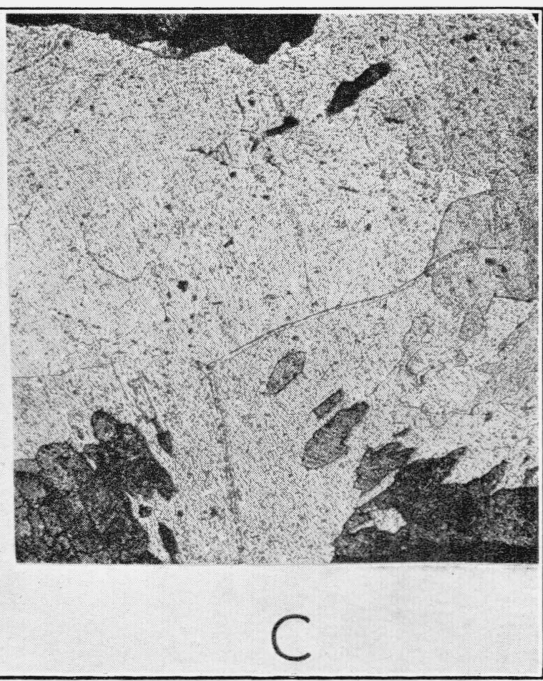

FIGURE 1.-Veining and network structures in alpha iron.

A. Alpha veining in electrolytic iron. $\times 100 . \quad$ B. Gamma network in ferrite grains. $\times 100 . \quad$ C. Delta network in ferrite grains. $\times 50$. [Rawdon and Berglund $(28)$.] 


\section{COMPRESSIBILITY}

Bridgman (12) found that the mean value for the cubic compressibility of open-hearth (Armco) iron, for pressures between 0 and $10,000 \mathrm{~kg} / \mathrm{cm}^{2}$, was $0.566 \times 10^{-6} / \mathrm{kg} / \mathrm{cm}^{2}$ at $30^{\circ} \mathrm{C}$ and $0.572 \times 10^{-6}$ at $75^{\circ}$ C. Unpublished data obtained by Dr. L. H. Adams of the Geophysical Laboratory, Carnegie Institution of Washington, showed the compressibility of a sample of high-purity iron to be the same, within 1 part in 500, as that of a sample of Bessemer steel. Evidently compressibility is not greatly affected by minor changes in composition.

\section{MELTING POINT AND HEAT OF FUSION}

The melting points of several metals have been determined with sufficient accuracy so that they are used as fixed points on the pyrometric scale, but this applies to metals which are readily obtained in states of higher purity than has been possible for iron. The difficulty of obtaining high-purity iron, the lack of accurate information regarding the purity of the samples used for melting-point determinations, and the difficulties in pyrometric observations at temperatures of $1,500^{\circ} \mathrm{C}$, or higher, all help to account for the lack of agreement in the results obtained in different determinations of the melting point of iron.

Eight published values have been selected as being the best with respect both to purity of material and to pyrometric procedure. Corrections of some of these values are necessary, however, on account of changes in the pyrometric scale and in radiation formulas, which have been made since the determinations were reported. These corrected values range from $1,527^{\circ} \mathrm{C}$, reported by Jenkins and Gayler (40), to $1,537^{\circ} \mathrm{C}$, reported by Burgess and Waltenberg (6). The numerical average of the eight values is $1,534^{\circ} \mathrm{C}$, which is rounded to $1,535^{\circ} \mathrm{C}\left(2,795^{\circ} \mathrm{F}\right)$ as the best present approximation of the melting point of iron.

A review of the diversified values obtained by different investigators suggests the rounded value $65 \mathrm{cal} / \mathrm{g}$ or $3,630 \mathrm{cal} / \mathrm{g}$-atom as the best present approximation for the heat of fusion of iron.

\section{BOILING POINT AND HEAT OF VAPORIZATION}

The boiling point of iron is so high that direct determinations are not practicable; the method most frequently employed is extrapolation of data for the vapor pressure of molten iron at various temperatures. The rounded value $3,000^{\circ} \mathrm{C}\left(5,430^{\circ} \mathrm{F}\right)$ defines the probable boiling point of iron as closely as the data warrant.

From thermodynamic consideration of thermal data, Kelley (68) calculated that the heat of vaporization of iron at the boiling point is $1,515 \mathrm{cal} / \mathrm{g}$ or $84,620 \mathrm{cal} / \mathrm{g}$-atom. However, $2,735^{\circ} \mathrm{C}$ was used as the boiling point of iron, a value which is considerably lower than the selected value of $3,000^{\circ} \mathrm{C}$.

\section{MECHANICAL PROPERTIES}

\section{(a) TENSILE PROPERTIES}

Freshly deposited electrolytic iron may possess a tensile and a yield strength of more than $100,000 \mathrm{lb} / \mathrm{in}^{2}{ }^{2}$, with an elongation as small as 3 percent (gage length not given). For the same material 
in the annealed condition, tensile strength between 40,000 and 55,000 $\mathrm{lb} /$ in. ${ }^{2}$, yield strength between 20,000 and $25,000 \mathrm{lb} / \mathrm{in}^{2}{ }^{2}$, and elongation between 25 and 45 percent (gage length usually about 2 in.), have been reported. Such values are roughly comparable with those obtained with open-hearth (Armco) iron. Fusion in vacuum with subsequent annealing further softens electrolytic iron. The reported properties of such material are: tensile strength between 35,000 and $40,000 \mathrm{lb} / \mathrm{in}^{2}{ }^{2}$, yield strength between 10,000 and $20,000 \mathrm{lb} / \mathrm{in} .{ }^{2}$, elongation of 30 to 60 percent in a gage length of 1.5 in., and reduction of area between 70 and 90 percent.

The tensile strength of electrolytic iron decreases with increasing testing temperature up to about $100^{\circ} \mathrm{C}$, then rises to a maximum at about $250^{\circ} \mathrm{C}$, and decreases with further increase in temperature. The temperature of maximum strength in electrolytic iron is somewhat lower than the "blue-heat" range of commercial steels. The

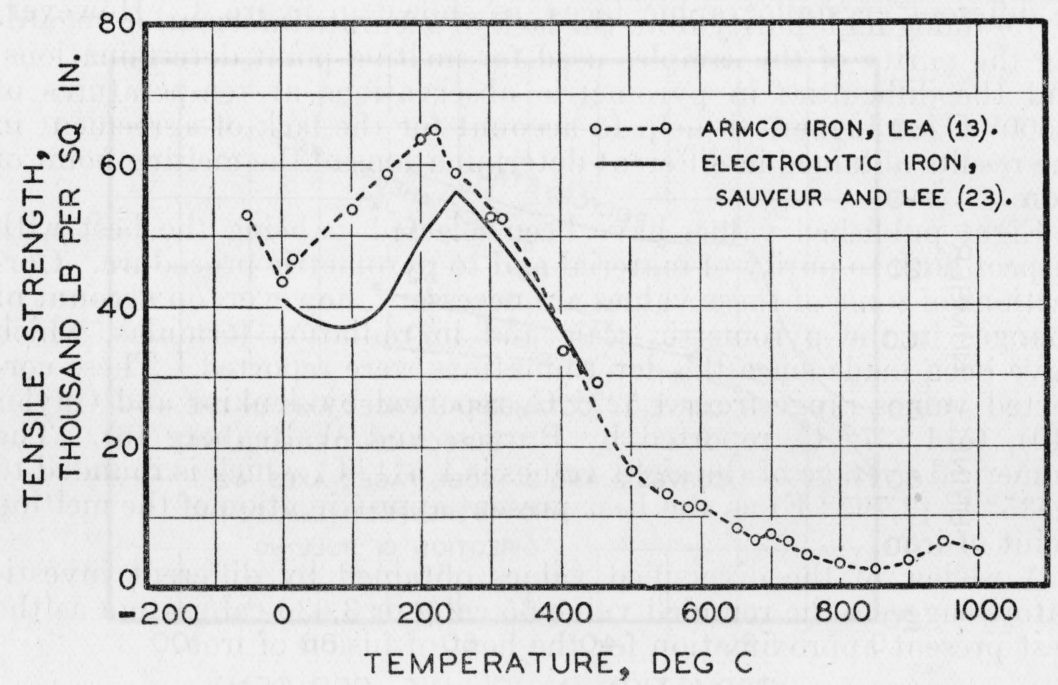

Figure 2.-Tensile strength of open-hearth (Armco) iron and of electrolytic iron at various temperatures.

effect of increasing temperature on the tensile strength of electrolytic and of open-hearth irons is shown in figure 2 .

Tensile properties of single-crystal specimens have been reported only for material which approximated the composition of Armco iron, for which tensile strengths of 20,000 to $35,000 \mathrm{lb} / \mathrm{in}^{2}{ }^{2}$, yield strengths of 4,000 to $9,000 \mathrm{lb} / \mathrm{in}^{2}$, and elongations for 1 -in. gage length of 30 to 85 percent were obtained.

\section{(b) ELASTIC PROPERTIES}

Abram (52) concluded that Young's modulus of pure iron in the annealed condition should be about $30,000,000 \mathrm{lb} / \mathrm{in}^{2}$. The elastic moduli of single-crystal specimens of iron vary in the direction of different crystallographic axes (62). Goens and Schmid (46) reported that Young's modulus in a single crystal of open-hearth (Armco) iron was $19,000,000 \mathrm{lb} / \mathrm{in}^{2}{ }^{2}$ in the direction of the cube axis (the [100] direction) and $41,000,000 \mathrm{lb} / \mathrm{in}^{2}{ }^{2}$ in the direction of the cube diagonal (the [111] direction). 
The modulus of elasticity of open-hearth (Armco) iron decreases as the temperature increases up to about $500^{\circ} \mathrm{C}(13,29)$.

\section{(c) HARDNESS}

Brinell numbers as low as 50 for fully annealed electrolytic iron, and as high as 360 for freshly deposited metal, have been reported. Brinell numbers between 60 and 70 are frequently reported for vacuum-melted electrolytic iron as well as for other forms of highpurity iron and for open-hearth iron in the annealed condition. The Brinell number of electrolytic iron can be increased to about 200 by cold work (27), but the rate of increase is not so rapid for electrolytic iron as for open-hearth steel (21).

The Brinell number of iron is not appreciably affected by variation in grain size and, in single-crystal specimens subjected to cold rolling, there is no very significant difference in the ball-indentation hardness of different crystallographic faces, as shown in figure 3 . However,

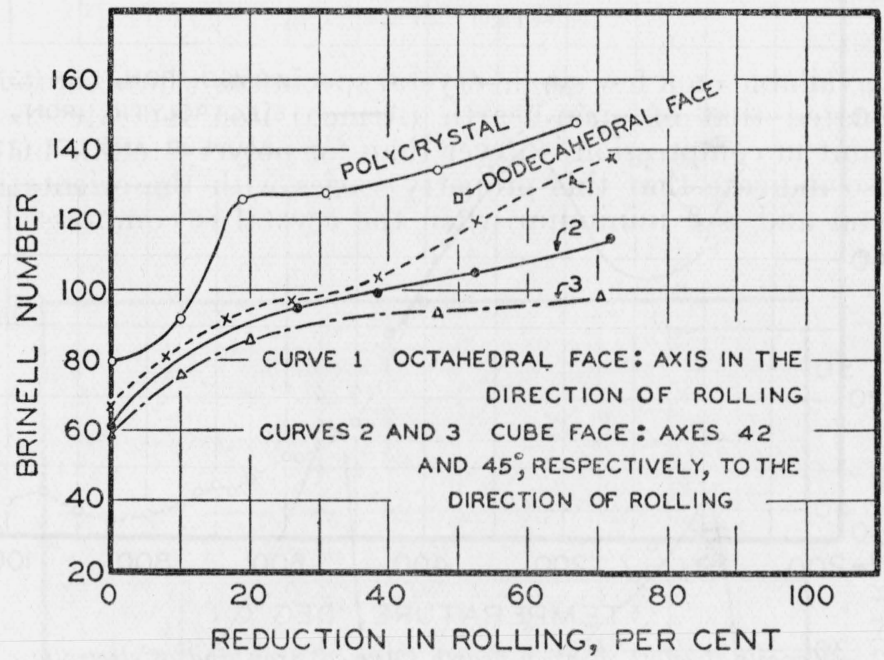

FiguRE 3.-Variation of hardness with degree of rolling of polycrystalline iron and of single-crystal specimens with different orientation.

[Gries and Esser (32).]

there appears to be a difference in the rate of work hardening in different crystallographic directions.

With a slight increase in the testing temperature the hardness of fairly pure iron is decreased slightly. Further increase in temperature is accompanied by an increase in hardness, which reaches a maximum at about $200^{\circ} \mathrm{C}$; above this point increases in temperature result in a progressive decrease in hardness, figure 4 . On the other hand, according to O'Neill (37), determinations of scratch hardness show a continual decrease in hardness with increasing temperature.

(d) STRENGTH IN COMPRESSION

The properties of open-hearth (Armco) iron in compression according to Moore and Kommers (11) are as follows:

Elastic limit $19,400 \mathrm{lb} / \mathrm{in}^{2}$.

Proportional limit.

Yield strength $20,600 \mathrm{lb} /$ in $^{2}$ 


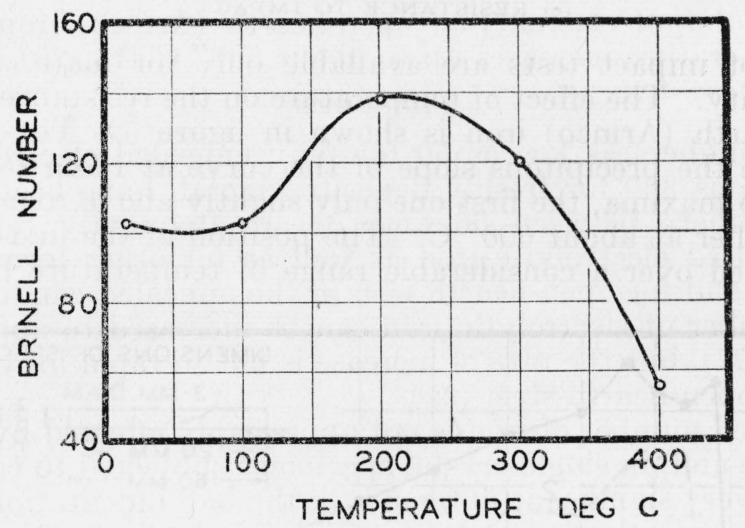

FIGURE 4.-Brinell numbers of open-hearth (Armco) iron at various temperatures. [Tapsell and Clenshaw (29).]

Data available on a few single-crystal specimens whose composition approximated that of open-hearth (Armco) iron indicate that the elastic limit in compression is lower than for polycrystalline material. They also indicate that this property varies with the orientation of the crystal and is a minimum when the crystal is compressed on a cube face.

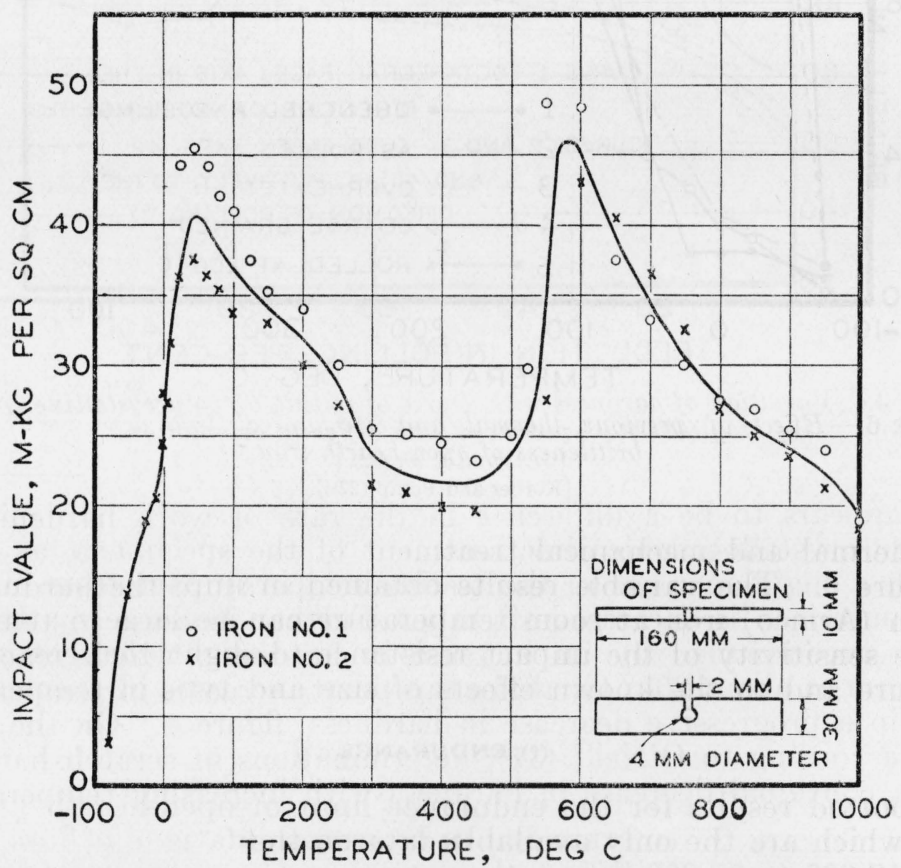

FIGURE 5.-Results of impact tests on open-hearth iron.

[Goerens and Hartel (4).] 
(e) RESISTANCE TO IMPACT

Results of impact tests are available only for material of commercial purity. The effect of temperature on the resistance to impact of open-hearth (Armco) iron is shown in figure 5. The significant features are the precipitous slope of the curve at room temperature and the two maxima, the first one only slightly above room temperature, the other at about $600^{\circ} \mathrm{C}$. The position of the first maximum can be varied over a considerable range of temperature by varying

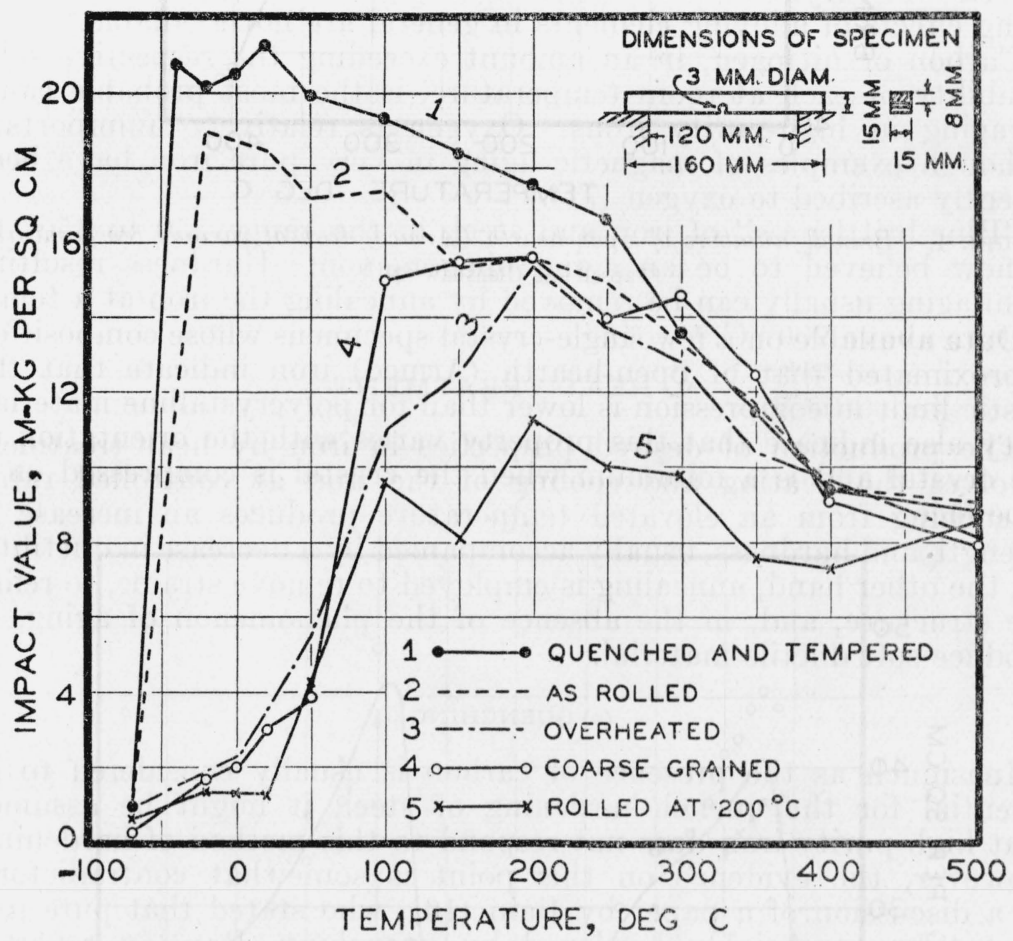

FIGURE 6.-Effect of previous thermal and mechanical treatment on the notch brittleness of open-hearth iron.

[Körber and Pomp (22).]

the thermal and mechanical treatment of the specimens, as shown in figure 6 . The variable results obtained in impact tests of openhearth (Armco) iron at room temperature can be largely attributed to the sensitivity of the impact resistance to slight changes in temperature and to the known effects of size and type of specimens.

\section{(f) ENDURANCE}

Reported results for the endurance limit of open-hearth (Armco) iron, which are the only available data on the fatigue of iron, range from 12,000 to $38,000 \mathrm{lb} / \mathrm{in} .^{2}$, the variations in conditions of test and the size and previous history of the specimen being responsible for the lack of precision. Values between 24,000 and $28,000 \mathrm{lb} / \mathrm{in}^{2}{ }^{2}$ have frequently been reported. 
(g) EFFECT OF AGING

Since the phenomenon of aging, or change in the properties of metals with time, is associated with the presence of minor constituents or impurities, aging effects would be expected to decrease in magnitude with increasing purity of the material. Aging has not been observed in vacuum-melted electrolytic iron, but does occur in iron of commercial purity as a result of the presence of carbon, nitrogen, or copper (43). Aging has been observed to result from the presence of beryllium or tungsten in steel, but complete data on the aging effects of alloying elements in general are not available.

Carbon or nitrogen, in an amount exceeding the respective solid solubility of each at room temperature, is the most probable cause of aging in high-purity irons. Oxygen is relatively unimportant although examples of magnetic aging in very pure iron have been recently ascribed to oxygen (71).

"Blue brittleness" of iron and steel, in the range 250 to $350^{\circ} \mathrm{C}$, is now believed to be an aging phenomenon. Hardness resulting from aging usually can be removed by annealing the iron at a temperature above $200^{\circ} \mathrm{C}$.

\section{HEAT TREATMENT}

The production of desired properties in iron by heat treatment involves the heating and cooling of the iron at controlled rates. Quenching from an elevated temperature produces an increase in strength and hardness, usually accompanied by a decrease in ductility. On the other hand, annealing is employed to remove strains, to refine the structure, and, in the absence of the phenomenon of aging, to produce soft ductile material.

(a) QUENCHING

Inasmuch as the presence of carbon is usually considered to be essential for the quench-hardening of steel, it might be assumed that high-purity iron does not respond to this method of hardening. However, the evidence on this point is somewhat contradictory. In a discussion of a paper by Bain (16), who stated that pure iron cannot be appreciably hardened by quenching, Rawdon reported that small areas on a specimen of electrolytic iron, containing 0.02 percent of carbon, had been decidedly hardened by heating in air with a high-potential spark, with subsequent cooling at an extremely rapid rate. A Widmanstätten or martensitic structure was developed by Sauveur and Chou (39) in electrolytic iron by drastic quenching from above $A_{3}$, and Mehl and Smith (64) found that a similar structure could occasionally be obtained in quenched electrolytic iron which contained only 0.004 percent of carbon.

Kenyon (33) has shown that a Brinell number of 110 was obtained for basic open-hearth iron quenched in water from $940^{\circ} \mathrm{C}$ after hot rolling, whereas a Brinell number of about 80 is characteristic of the same material annealed at $900^{\circ} \mathrm{C}$ and slowly cooled.

\section{(b) ANNEALING}

Freshly deposited electrolytic iron contains relatively large amounts of hydrogen and is brittle. Annealing at any temperature above room temperature reduces the hydrogen content and the hardness, 
but the maximum results are obtained only by heating above $A_{3}$, as is shown in figure 7. Likewise, the effects of cold working are only partially removed by heating to 500 or $600^{\circ} \mathrm{C}$, as is shown in figure 8; complete recovery of the cold-worked metal requires annealing at temperatures of at least $800^{\circ} \mathrm{C}$.

The microstructure of cathode electrolytic iron is not greatly affected by annealing unless the temperature is above $A_{3}$, under which condition the structure changes rapidly to that of allotriomorphic grains characteristic of ordinary ferrite.

Recrystallization of ferrite which has been strained by coldworking may begin at a temperature as low as $400^{\circ} \mathrm{C}$. The rate

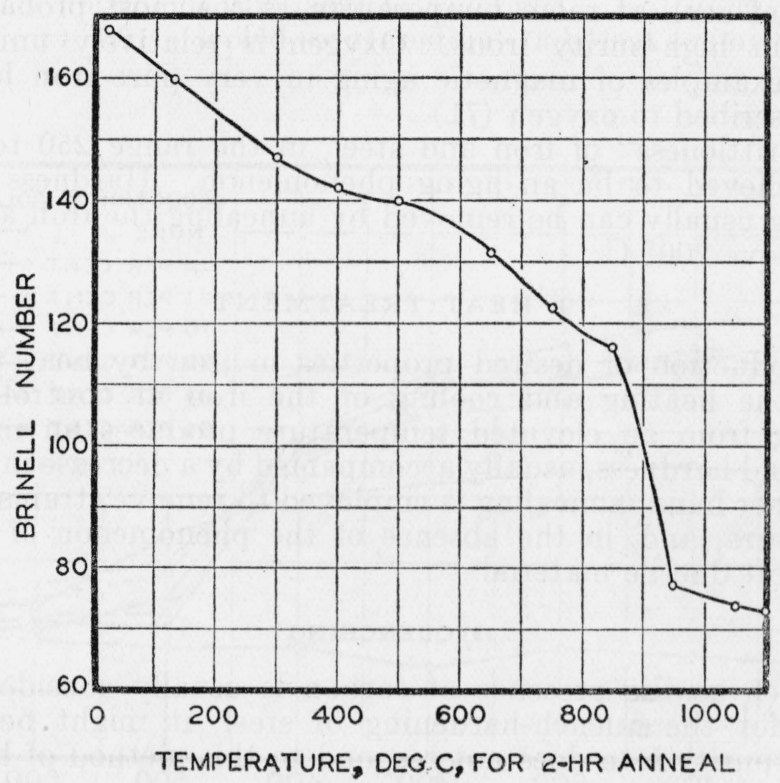

FIGURE 7.-Effect of annealing on the Brinell hardness of cathode electrolytic iron.

[Cazaud and Hugues (20).]

of recrystallization increases slowly with increase of temperature up to about $700^{\circ} \mathrm{C}$ and more rapidly from $700^{\circ} \mathrm{C}$ to the $\mathrm{A}_{3}$ point. Annealing characteristics depend upon the extent of the previous cold-work.

The strain-anneal method for the production of abnormally large crystals or of monocrystalline specimens appears to be practicable for iron of commercial purity, but of doubtful merit for purer forms of iron. Oberhoffer and his associates (14) found that maximum grain growth in commercial iron appeared after 10-percent deformation followed by annealing at 700 to $800^{\circ} \mathrm{C}$, but could not establish (18) the corresponding conditions for electrolytic iron, although Stead and Carpenter (5) had previously reported a change of this kind in cold-worked electrolytic iron, after heating for a short time at a temperature slightly above $\mathrm{A}_{3}$, followed by slow cooling to room temperature. However, abnormally large crystals were obtained only in thin sheets of electrolytic iron, about 0.01 in. in thickness. 
Impurities present in commercial irons appear to facilitate the production of very large crystals.

\section{PLASTIC DEFORMATION}

The capacity of iron for plastic deformation and the ease with which deformation may be accomplished, increase with increasing temperature for each of the allotropic forms. The disappearance of plasticity at very low temperature was studied by Heindlhofer (61), who concluded that different tests, such as torsion, impact, and tensile tests, involve different combinations of stresses and, consequently, the relation between temperature and plasticity varies with the type of test. Evidence of plasticity in torsion was lacking only in specimens tested at temperatures below $-190^{\circ} \mathrm{C}$.

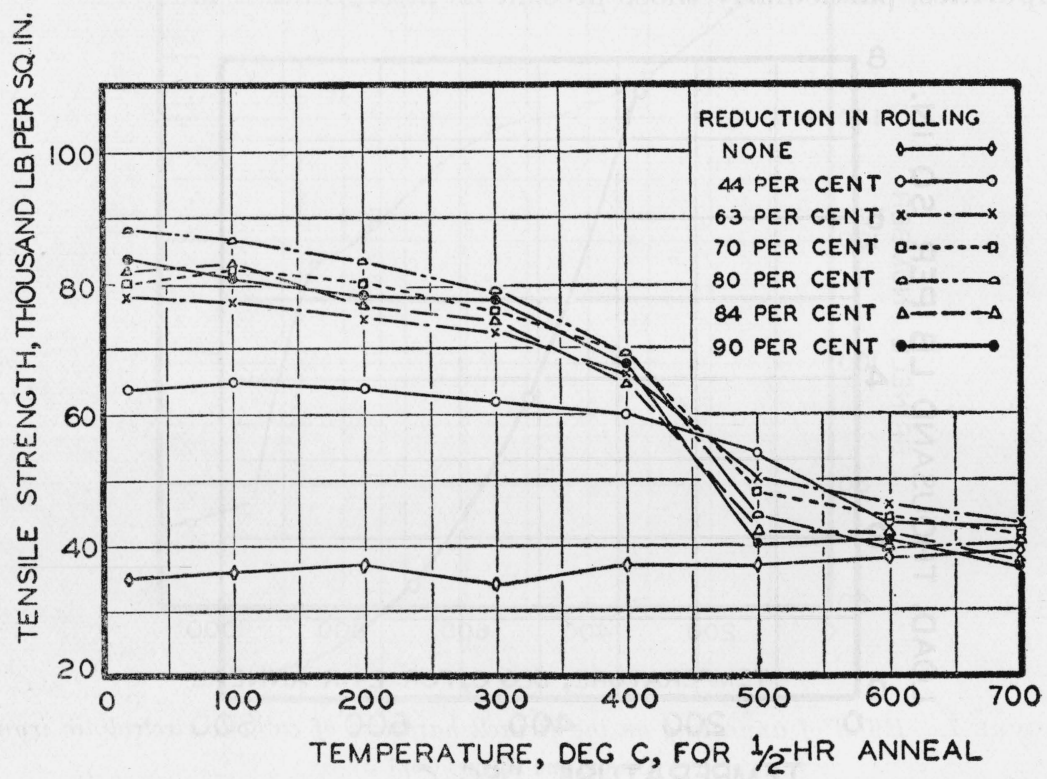

FIGURE 8.- Effect of annealing on the tensile strength of cold-rolled electrolytic iron.

[Freeman (24).]

The first visible evidence of plastic deformation of iron stressed in tension at ordinary temperature is the macroscopic surface condition known as Piobert or Lüders lines, "worms", or "stretcher strains." Microscopical examination shows evidence within many of the grains of deformation by slip. With increasing deformation, the grains in which slip bands occur increase in number and the directions of slip within the various individual grains no longer indicate a general prevailing direction of deformation. With greater deformation the grains become elongated and otherwise distorted. The mechanism of the first stages of plastic deformation has been extensively investigated. Most recent investigators agree with Mathewson (49) in the theoretical conclusion that plastic deformation of an iron crystal occurs in the direction of a line of closest atom packing by block movement on planes of the densest atom packing. Difficulty is experienced in 
determining the orientation of the slip planes, according to Mathewson, because of the tendency toward rotation which accompanies block movement in a crystal under stress, with consequent increase of stress in other eligible slipping directions. In ordinary polycrystalline material the process is further complicated by inhomogeneity of the force field at the grain boundaries.

The decreased elastic limit of iron with increasing temperature and the increased atomic mobility which tends to decrease or to prevent work hardening in the material, are reflected in the increased ease and capacity for plastic deformation in iron with increasing temperature. Marked changes in the deformation characteristics occur at the temperatures of the allotropic transformations and irregularities also may be due to solubility phenomena of alloying elements or impurities, particularly those present as intergranular material.

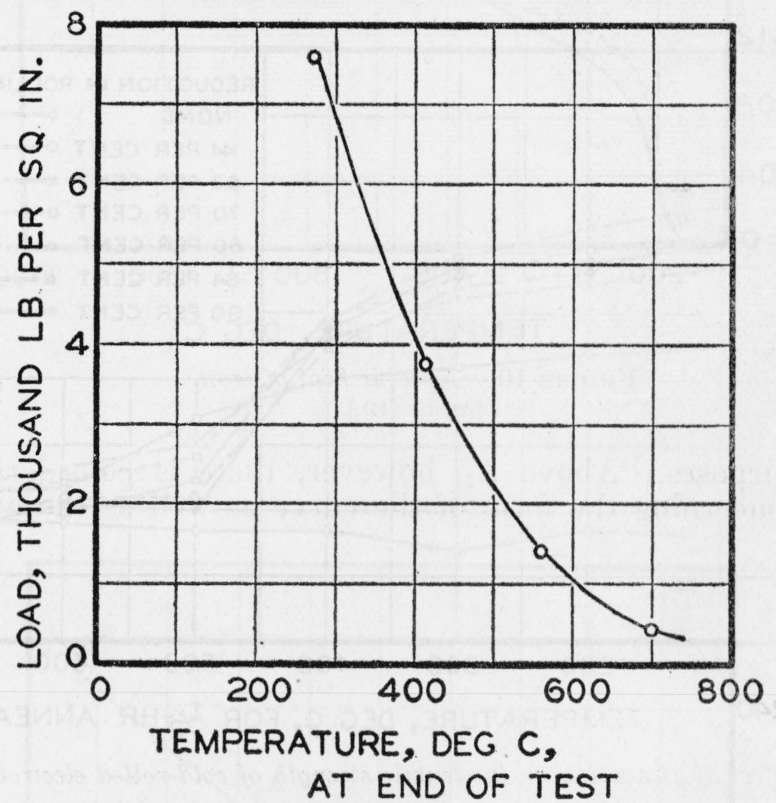

FIgURE 9.-Stress-temperature relation in iron after 150-hour tests. [Austin and Gier (54).]

The recent recognition of the importance of the time factor in the plastic deformation of iron has led to the development of a variety of "creep tests", mostly conducted at elevated temperatures and on structural metals. One of the tew studies of the "creep" of highpurity iron is that of Austin and Gier (54) of the applicability of the Rohn method of test. Figure 9 shows how the load-carrying capacity decreases with increasing temperature in this test.

\section{THERMAL PROPERTIES}

(a) SPECIFIC HEAT

Available information on the specific heat of iron at various temperatures has been summarized byAustin (44) in the curves shown in 
figure 10. Up to the $A_{2}$ point the form of this curve has been established and the accuracy of the best data is probably sufficient for

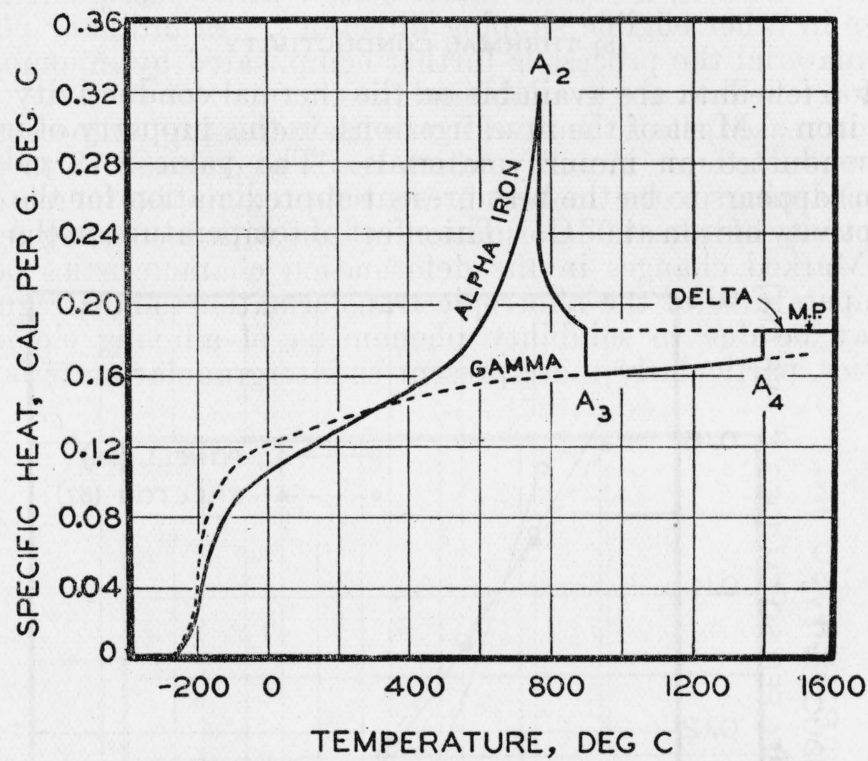

FIGURE 10.-Specific heat of iron.

[Austin (44).]

practical purposes. Above $A_{2}$, however, there is considerable uncertainty concerning the form of the curve as well as the numerical

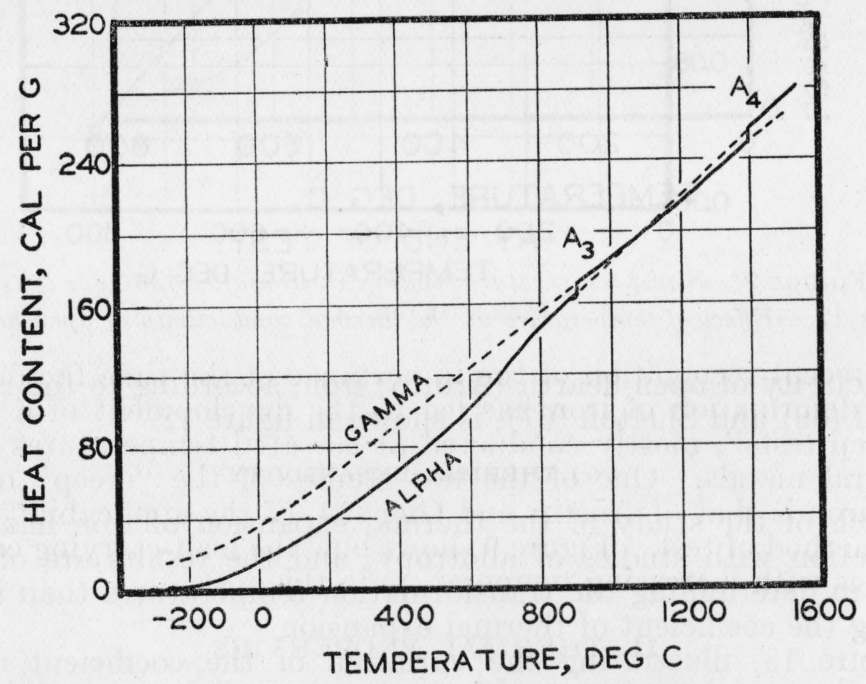

FIGURE 11.- Heat content of iron. (Austin (45).]

values. There is need for more precise determinations of the heat capacity of gamma and delta iron. 
Changes in the heat content at the transformation points, which are shown graphically in figure 11 , amount to $3.86 \mathrm{cal} / \mathrm{g}$ at $\mathrm{A}_{3}$ and 1.7 $\mathrm{cal} / \mathrm{g}$ at $\mathrm{A}_{4}$. There is apparently no heat effect at $\mathrm{A}_{2}$.

\section{(b) THERMAL CONDUCTIVITY}

Only a few data are available on the thermal conductivity of highpurity iron. Most of the investigations on this property of iron have been conducted on impure materials. The value $0.19 \mathrm{cal} / \mathrm{sec} / \mathrm{cm}^{2}$ $\left({ }^{\circ} \mathrm{C} / \mathrm{cm}\right)$ appears to be the best present approximation for the thermal conductivity of iron at $0^{\circ} \mathrm{C}$. The effect of temperature on the thermal

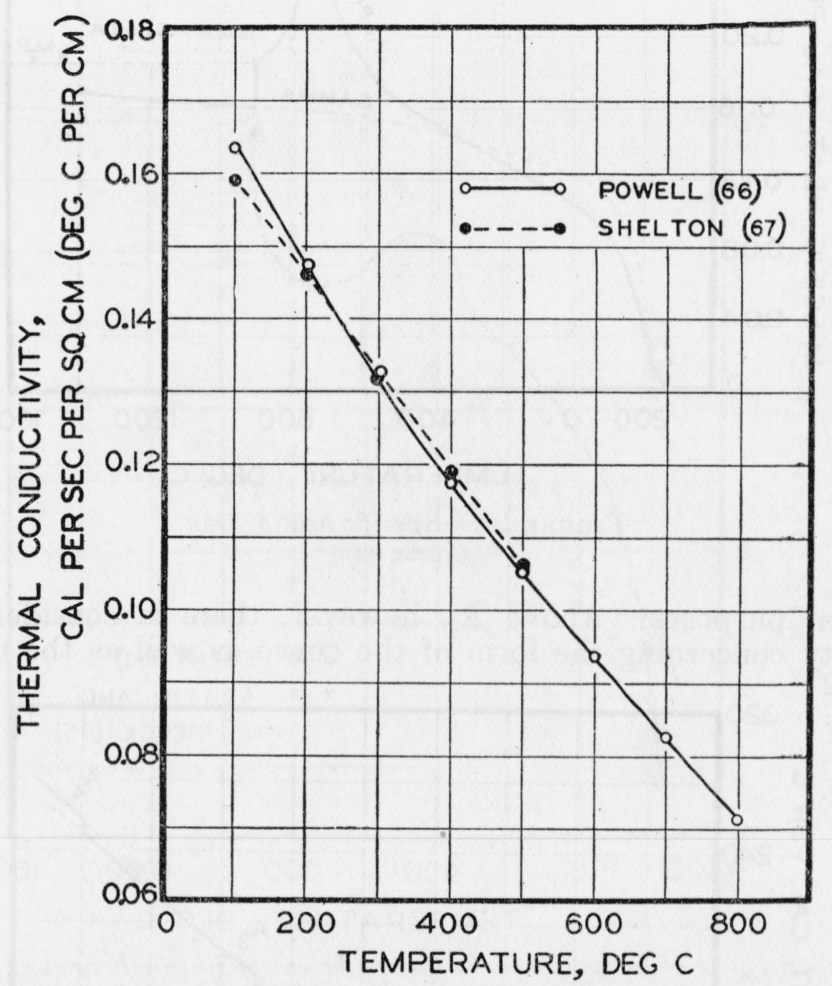

FIGURE 12.-Effect of temperature on the thermal conductivity of open-hearth iron.

conductivity of open-hearth (Armco) iron, according to the results of Powell (66) and Shelton (67), is shown in figure 12.

\section{(c) THERMAL EXPANSIVITY}

Much of the study of the thermal expansion of iron has been in connection with studies of allotropy, and the results are of greater value in determining the transformation temperatures than in determining the coefficient of thermal expansion.

Figure 13, illustrating the variation of the coefficient of linear thermal expansion of iron with temperature, is based mainly on the data of Ebert (31) and of Austin and Pierce (55). The precise determination of the coefficient becomes increasingly difficult with increasing temperature, and Austin and Pierce concluded that precise coefficients 
cannot be given for the temperature range from $600^{\circ} \mathrm{C}$ to the $\mathrm{A}_{3}$ point. The expansion may vary from sample to sample because of small differences in composition or previous treatment.

Solidification of molten iron is accompanied by a decrease in volume of about 5 percent. During the $A_{4}$ transformation there is a sudden contraction during cooling or an expansion during heating for which values ranging from 0.00085 to 0.0032 have been reported for $\Delta L / L$. The thermal expansion effect at $A_{3}$ is in the reverse direction to that at $A_{4}$; at $A_{3}$ there is a sudden contraction during heating and

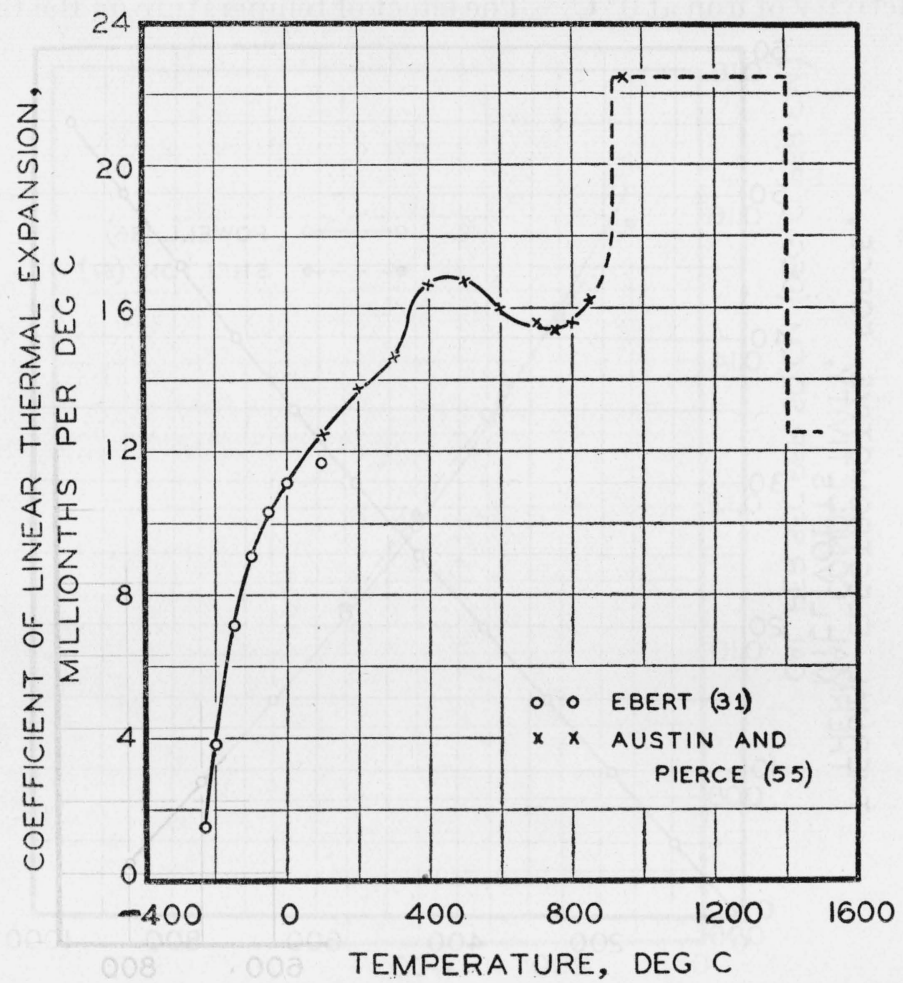

FIGURE 13.-Effect of temperature on the coefficient of linear thermal expansion of iron.

an expansion during cooling, with reported values for $\Delta L / L$ ranging from 0.00016 to 0.0038 . The expansion and contraction of a particular sample are not always equal; permanent change in dimensions may result from repeated heating and cooling through $\mathrm{A}_{3}$. Abnormality in thermal expansion has not been observed at $\mathrm{A}_{2}$.

(d) THERMAL ELECTROMOTIVE FORCE

Although the thermal electromotive force of one pure metal against another is a constant for that particular combination, this property is considerably affected by the presence of local impurities and by the previous thermal and mechanical history of both metals. Sufficient data regarding the thermal electromotive force of pure iron and the effect of small amounts of impurities are not available as yet to permit the use of this determination as an indicator of purity in iron. 
Thermocouples of iron with another metal such as aluminum, copper, lead, nickel, platinum, or tin have been studied but, in general, the thermal electromotive force of such a couple is small, varies in an irregular manner with temperature, and is not reproducible in other similar thermocouples. The only one which has been found useful is the combination of iron with constantan, the latter name being used to refer to a type of alloy rather than a single rigidly defined composition. Consequently, there are several constantans each with its own emf against iron. However, the relatively large potential developed by this combination and the approximately constant slope

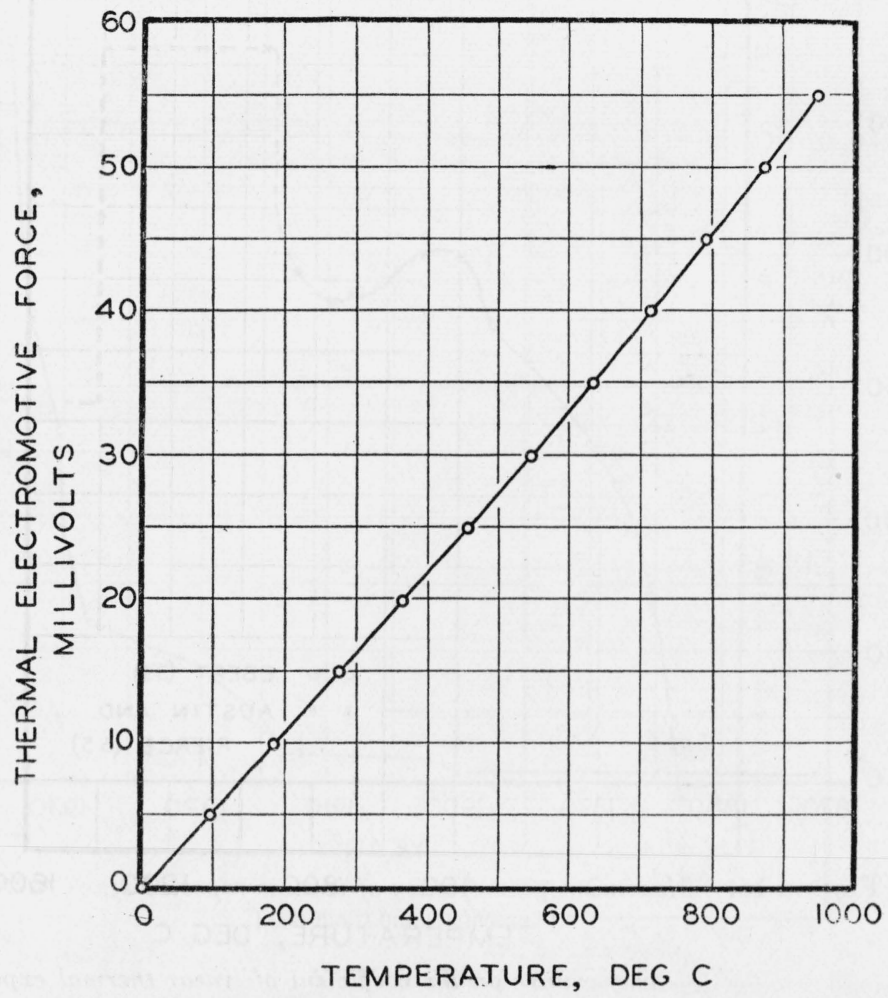

FigURE 14.-Thermal electromotive force of iron versus constantan. [International Critical Tables (25).]

of the curve between 0 and $1,000^{\circ} \mathrm{C}$ make it useful within this temperature range. Figure 14, showing the thermal electromotive force of an iron-constantan thermocouple at various temperatures, is typical of iron-constantan thermocouples in general, but the numerical values vary with different samples.

\section{RESISTIVITY}

The resistivity of iron is affected by the presence of impurities and by the previous mechanical and thermal treatment of the specimen. The effect of a given impurity is not always a linear one; for example, according to Yensen (19) a change in carbon content under 0.02 
percent had eighteen times as much effect on the resistivity as did an equal change above 0.02 percent. Small changes in the resistivity as a result of application of pressure to the specimen have been reported by Beckman (7) and Bridgman (9).

A review of available information indicates that the rounded value, 9.8 microhm-cm, is the best approximation for the resistivity of iron at $20^{\circ} \mathrm{C}$. Likewise, the rounded value $0.0065 /{ }^{\circ} \mathrm{C}$ appears to be the best approximation for the fundamental coefficient, i. e., the temperature coefficient of resistivity per degree between 0 and $100^{\circ} \mathrm{C}$.

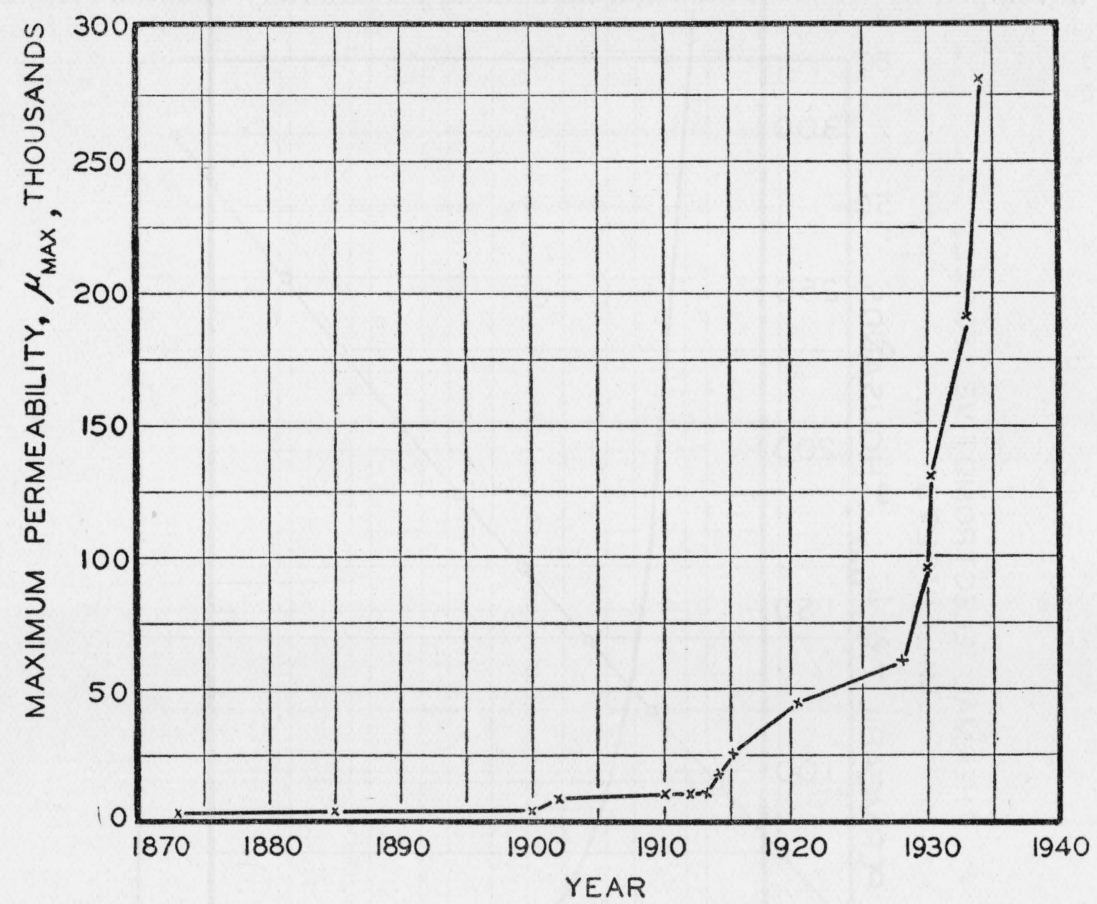

FIGURE 15.-Maximum permeability of iron as reported since 1873. [Yensen (47) and Cioff (58).]

\section{EMISSIVITY}

Emissivity is the ratio between the amounts of radiant energy emitted by iron and by a black body at the same temperature and is the only optical property of iron which is of practical importance. This property varies with the wave length of light and in optical pyrometry a correction is applied for the emissivity at an effective wave length of about $0.65 \mu$.

Few data are available on the emissivity of high-purity irons, but many determinations have been made on iron and steel under conditions of plant operation, on liquid steel containing slag and various floating objects, or on solid metal during hot-working operations when the surface was covered with a scale of iron oxide, for which values ranging from 40 to 90 percent have been reported. The emissivity for $0.65 \mu$ of a bright surface of high-purity iron, either solid or liquid, according to the best available data (8) is about 37 percent. 


\section{MAGNETIC PROPERTIES}

The magnetic properties of iron are so drastically affected by the presence of impurities, by the size and shape of the specimens, and by the previous thermal and mechanical treatment, that magnetic data, in general, represent the characteristics only of particular specimens. Appreciation of these factors has developed within quite recent years

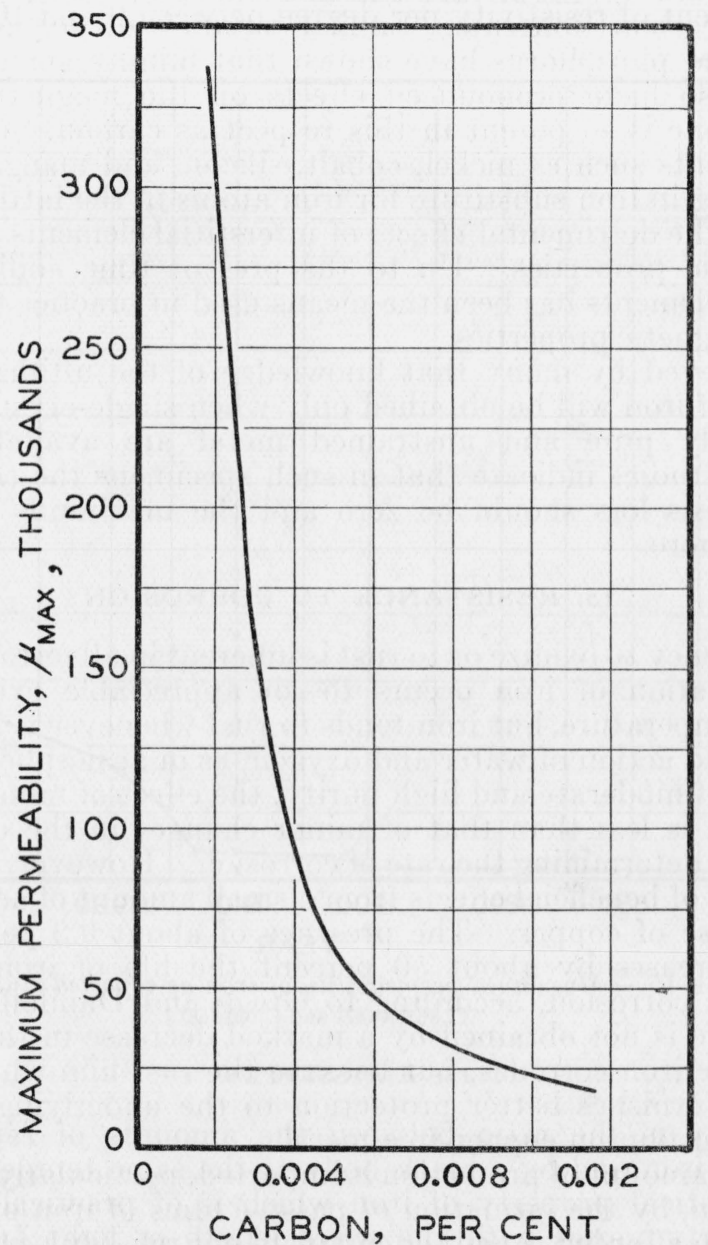

FIGURE 16.-Effect of carbon content on the maximum permeability of a single crystal of oxygen-free iron.

[Yensen and Ziegler (72).]

and is reflected in the changing opinion from year to year as to what constitutes the maximum in magnetic properties that can be obtained in iron. Figure 15 shows that relatively very low permeabilities were the best that could be obtained prior to 1900 . The introduction of electrolytic iron about 1900 was accompanied by an improvement in magnetic properties which was negligible, however, in comparison with that which has been achieved since about 1914. The most recent 
development is the treatment of high-purity iron in hydrogen at temperatures approaching the melting point, by which permeabilities as high as 280,000 have been attained.

Recent studies have shown that very small amounts of certain impurities, which because of their interstitial position distort the lattice structure, have surprisingly large effects on the magnetic properties of iron. The most striking effect so far reported is that of carbon; Figure 16 shows the extreme effect of small variations in very low carbon contents. Similar studies of oxygen, sulphur, nitrogen, and phosphorus have shown that minute amounts of these elements also have pronounced effects on the magnetic properties although none is so potent in this respect as carbon. On the other hand, elements such as nickel, cobalt, silicon, and manganese, which on dissolving in iron substitute for iron atoms in the lattice structure, counteract the detrimental effects of interstitial elements and improve the magnetic properties. Up to the present time addition of substitutional elements has been the means used in practice for obtaining superior magnetic properties.

It is believed by many that knowledge of the ultimate magnetic properties of iron will be obtained only when single-crystal specimens of absolutely pure and unstrained metal are available. Recent laboratory studies indicate that in such specimens the coercive force and hysteresis loss should be zero and the maximum permeability 500,000 or more.

\section{RESISTANCE TO CORROSION}

The tendency to oxidize or to rust is inherent in all ferrous materials. Direct oxidation of iron occurs to an appreciable extent only at elevated temperature, but iron tends to rust whenever it is exposed to the combined action of water and oxygen, as in atmospheric exposure.

In irons of moderate and high purity, the effect of minor changes in composition is less than that of minor changes in the conditions of exposure, in determining the rate of corrosion. However, an outstanding example of beneficial effects from a small amount of added element is in the case of copper. The presence of about 0.2 percent of this element increases by about 50 percent the life of iron exposed to atmospheric corrosion, according to Gregg and Daniloff (60). This increased life is not obtained by a marked decrease in the initial rate at which the iron corrodes, but because the rust film which forms on this metal furnishes better protection to the underlying metal than does the rust film on copper-free metal.

A certain amount of protection is imparted, particularly to the purer forms of iron, by the formation of passive films of iron oxide, but the protection so afforded is neither complete nor reliably permanent.

Satisfactory resistance to corrosion in ferrous metals is obtained only in the presence of substantial amounts of elements, for example silicon or chromium, the amount being such that the product should properly be considered an alloy.

\section{MISCELLANEOUS PROPERTIES}

There are a number of minor properties or effects which have received consideration by investigators. Included in this miscellaneous group are thermoelectric effects such as the Peltier and Thomson 
effects, mechanomagnetic, galvanomagnetic, and thermomagnetic effects, reflectivity, and $\mathrm{X}$-ray absorption. With one exception these properties or effects are of interest only in theoretical considerations. The one exception, which has a practical significance, is magnetostriction, the dimensional change during magnetization. This effect is believed to be largely responsible for the noise in electrical transformers and in loud speakers.

\section{SELECTED REFERENCES}

(1) Annual report of the Physikalisch-Technische Reichsanstalt for 1909, p. 190 (Julius Springer, Berlin).

(2) B. Lambert and J. C. Thomson, J. Chem. Soc. 97, 2426 (1910).

(3) G. P. Baxter and C. R. Hoover, J. Am. Chem. Soc. 34, 1657 (1912).

(4) P. Goerens and G. Hartel, Z. anorg. Chem. 81, 130 (1913).

(5) J. E. Stead and H. C. H. Carpenter, J. Iron Steel Inst. 88, 119 (1913).

(6) G. K. Burgess and R. G. Waltenberg, Bul. BS 10, 79 (1914) S205.

(7) B. Beckman, Physik. Z. 16, 59 (1915).

(8) G. K. Burgess and R. G. Waltenberg, Bul. BS 11, 591 (1915) S242.

(9) P. W. Bridgman, Proc. Am. Acad. Arts Sci. 52, 571 (1916-1917).

(10) J. R. Cain, E. Schramm, and H. E. Cleaves, Bul. BS 13, 1 (1916-1917) S266; J. Ind. Eng. Chem. 8, 217 (1916).

(11) H. F. Moore and J. B. Kommers, Univ. Ill. Bul. 19, No. 8 (1921); (Bul. 124 of the Exp. Sta.).

(12) P. W. Bridgman, Proc. Am. Acad. Arts Sci. 58, 165 (1922-1923).

(13) F. C. Lea, Proc. Inst. Mech. Eng. 885 (1922); Engineering 113, 829 (1922).

(14) P. Oberhoffer and H. Jungbluth, Stahl u. Eisen 42, 1513 (1922).

(15) W. Blum and H. S. Rawdon, Trans. Am. Electrochem. Soc. 44, 397 (1923).

(16) E. C. Bain, Trans. Am. Inst. Min. Met. Eng. 70, 25 (1924).

(17) C. A. Edwards and L. B. Pfeil, J. Iron Steel Inst. 109, 129 (1924).

(18) P. Oberhoffer and W. Oertel, Stahl u. Eisen 44, 560 (1924).

(19) T. D. Yensen, Trans. Am. Inst. Elec. Eng. 43, 145 (1924).

(20) R. Cazaud and R. Hugues, Rev. mét. mém. 22, 218 (1925).

(21) J. R. Freeman, Jr. and R. D. France, Tech. Pap. BS 19, 297 (1925) T288.

(22) F. Körber and A. Pomp, Mitt. Kaiser-Wilhelm Inst. Eisenforschung 6, 33 (1925).

(23) A. Sauveur and D. C. Lee, J. Iron Steel Inst. 112, 323 (1925).

(24) J. R. Freeman, Jr., Trans. Am. Soc. Steel Treat. 10, 67 (1926).

(25) Int. Crit. Tables 1, 59 (McGraw-Hill Book Co., Inc., New York, 1926).

(26) N. A. deLangeron, Rev. univ. mines [7] 16, 145 (1927).

(27) L. B. Pfeil, Iron Steel Inst. (London) Carnegie Schol. Mem. 16, 153 (1927).

(28) H. S. Rawdon and T. Berglund, BS Sci. Pap. 22, 649 (1927-1928) S571.

(29) H. J. Tapsell and W. J. Clenshaw, Dept. Sci. Ind. Research, Eng. Res. Special Rep. no. 1, (1927).

(30) F. S. Tritton, Metallurgist 3, 88 (1927).

(31) H. Ebert, Z. Physik 47, 712 (1928).

(32) H. Gries and H. Esser, Arch. Eisenhüttenw. 2, 749 (1928-1929).

(33) R. L. Kenyon, Trans. Am. Soc. Steel Treat. 13, 240; 435 (1928).

(34) A. Mittasch, Z. angew. Chem. 41, 827 (1928).

(35) E. Ammermann and H. Kornfeld, Arch. Eisenhüttenw. 3, 307 (1929-1930).

(36) H. Gries and H. Esser, Arch. Elektrotech. 22, 145 (1929).

(37) H. O'Neill, J. Iron Steel Inst. 120, 207 (1929).

(38) H. Pincass, Chem. Z. 53, 525 (1929).

(39) A. Sauveur and C. H. Chou, Trans. Am. Inst. Min. Met. Eng. 84, 350 (1929).

(40) C. H. M. Jenkins and M. L. V. Gayler, Proc. Roy. Soc. (London) 129, 91 (1930).

(41) C. T. Thomas and W. Blum, Trans. Am. Electrochem. Soc. 57, 59 (1930).

(42) N. A. Ziegler, Trans. Am. Inst. Min. Met. Eng. 90, 209 (1930).

(43) E. W. Ehn, Metal Progress 20, 59; 108 (September 1931).

(44) J. B. Austin, J. Ind. Eng. Chem. 24, 1225 (1932).

(45) J. B. Austin, J. Ind. Eng. Chem. 24, 1388 (1932).

(46) E. Goens and E. Schmid, Mitt. deut. Materialprüfungsanstalten no. 19, 84 (1932). 
(47) T. D. Yensen, Phys. Rev. 39, 358 (1932).

(48) F. W. Aston, Mass Spectra and Isotopes, (Edwin Arnold and Co., London, 1933)

(49) C. H. Mathewson, National Metals Handbook, p. 392 (Am. Soc. Steel Treat., Cleveland, 1933).

(50) W. Schmidt, Ergebnisse der technischen Röntgenkunde. III. Wechselwirkung zwischen Röntgenstrahlen und Materie in Theorie und Praxis (p. 194) (Akademische Verlagsgesellschaft m. b. H., Leipzig, 1933).

(51) F. Winter, Metallbörse 23, 957 (1933).

(52) H. H. Abram, J. Iron Steel Inst. 129, 325 (1934).

(53) Anonymous, Engineering 138, 150 (1934).

(54) C. R. Austin and J. R. Gier, Trans. Am. Inst. Min. Met. Eng. 111, 53; 74 (1934)

(55) J. B. Austin and R. H. H. Pierce, Jr., Trans. Am. Soc. Metals 22, 447 (1934).

(56) G. P. Baxter, M. Curie, O. Hönigschmid, P. LeBeau, and R. J. Meyer. J. Am. Chem. Soc. 56, 753 (1934).

(57) P. P. Cioffi, Data presented to the Am. Phys. Soc., Washington, D. C. (April 1934).

(58) P. P. Cioffi, Phys. Rev. 45, 742 (1934)

(59) C. H. Desch, Proc. Inst. Mech. Eng. 127, 277 (1934).

(60) J. L. Gregg and B. N. Daniloff, The Alloys of Iron and Copper (McGrawHill Book Co., Inc., New York, 1934).

(61) K. Heindlhofer, Metals Technology (October 1934).

(62) R. Kimura and K. Ohno, Sci. Rep. Tohoku Imp. Univ. 23, 359 (1934).

(63) W. Kroll, Z. Elektrochem. 40, 303 (1934).

(64) R. F. Mehl and D. W. Smith, Trans. Am. Inst. Min. Met. Eng. 113, 203 (1934).

(65) L. Northcott, Metallurgist 10, 163 (1934).

(66) R. W. Powell, Proc. Phys. Soc. 46, 659 (1934).

(67) S. M. Shelton, J. Research NBS 12, 441 (1934) RP669.

(68) K. K. Kelley, U. S. Bur. Mines, Bul. Preprint (1935).

(69) D. R. Kellogg, Metals and Alloys 6, 97 (1935).

(70) C. Wells, R. A. Ackley, and R. F. Mehl, Trans. Am. Soc. Metals Preprint (1935).

(71) T. D. Yensen and N. A. Ziegler, Metals Technology (June 1935).

(72) T. D. Yensen and N. A. Ziegler, Trans. Am. Soc. Metals 23, 556 (1935).

Washington, December 6, 1935. 